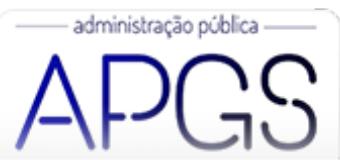

Administração Pública e Gestão Social ISSN: 2175-5787

apgs@ufv.br

Universidade Federal de Viçosa

Brasil

\title{
Mandatos Eleitorais e Ciclos Político- Orçamentários: Evidências dos Estados Brasileiros
}

Barrêto de Queiroz, Dimas; Freire de Morais, Lívia Maria; Silva Ferreira de Souza, Arthur Guilherme; Rebouças da Silva, Vanessa Karla

Mandatos Eleitorais e Ciclos Político-Orçamentários: Evidências dos Estados Brasileiros

Administração Pública e Gestão Social, vol. 11, núm. 2, 2019

Universidade Federal de Viçosa, Brasil

Disponível em: http://www.redalyc.org/articulo.oa?id=351558326008

Esta obra está bajo una Licencia Creative Commons Atribución-NoComercial-SinDerivar 3.0 Internacional. 


\title{
Mandatos Eleitorais e Ciclos Político-Orçamentários: Evidências dos Estados Brasileiros
}

\author{
Electoral Mandates and Political Budget Cycles: Evidences of Brazilian States \\ Mandatos electorales y ciclos políticos presupuestarios: evidencias de los estados brasileños
}

Dimas Barrêto de Queiroz

Universidade Federal do Rio Grande do Norte, Brasil

Redalyc: http://www.redalyc.org/articulo.oa?

dimasqueiroz@gmail.com

\section{Livia Maria Freire de Morais}

Universidade Federal da Paraíba, Brasil

liviamfm@gmail.com

\author{
Arthur Guilherme Silva Ferreira de Souza \\ Universidade Federal Rural do Semi-Árido, Brasil \\ arthurguilherme7@gmail.com
}

Vanessa Karla Rebouças da Silva

Universidade Federal da Paraíba, Brasil

vankrs@gmail.com

\section{Resumo:}

A literatura sobre ciclos político-orçamentários aponta que os gestores aptos a concorrer à reeleição possuem maiores incentivos para manipular gastos públicos em períodos eleitorais. Nesse sentido, o objetivo da pesquisa consistiu em averiguar a influência do mandato eleitoral sobre os gastos públicos dos governos estaduais brasileiros. A amostra foi composta pelos 26 estados brasileiros no período de 2003 a 2014, compreendendo três ciclos eleitorais. Utilizou-se como metodologia a técnica de regressão com dados em painel. A pesquisa concluiu que o comportamento oportunista é restrito aos governadores que estão em primeiro mandato e a manipulação é restrita aos investimentos. Percebeu-se uma alteração na composição dos gastos públicos em direção aos investimentos nos períodos eleitorais nos estados cujos governadores estão em primeiro mandato. Essa pesquisa contribuiu com a literatura nacional ao identificar o mandato eleitoral como um fator capaz de influenciar os gastos públicos estaduais nos períodos eleitorais.

Palavras-chave: Ciclos político-orçamentários, Mandatos eleitorais, Gastos públicos.

\section{ABSTRACT:}

The literature on political budget cycles indicates that managers able to run for re-election have greater incentives to manipulate public spending during election periods. That way, the objective of the research consisted in investigating the influence of the electoral mandate on the public expenditures of the Brazilian state governments. The sample was composed by the 26 Brazilian states from 2003 to 2014, for comprehending the three electoral cycles. The regression technique with panel data was used as methodology. The research concluded that opportunistic behavior is restricted to first-term governors and manipulation is restricted to investments. There has been a shift in the composition of public expenditures toward investment in election periods in states whose governors are in their first term. This research contributed to the national literature by identifying the electoral mandate as a factor capable of influencing state public spending in electoral periods.

KEYWORDs: Political budget cycles, Electoral mandates, Public expenditures.

\section{RESUMEN:}

La literatura sobre ciclos políticos presupuestarios indica que los gerentes que pueden postularse para la reelección tienen mayores incentivos para manipular el gasto público durante los períodos electorales. De esta forma, el objetivo de la investigación consistió 
en averiguar la influencia del mandato electoral en los gastos públicos de los gobiernos estatales brasileños. La muestra estuvo compuesta por los 26 estados brasileños de 2003 a 2014, por comprender los tres ciclos electorales. La técnica de regresión con datos de panel fue utilizada como metodología. La investigación concluyó que el comportamiento oportunista está restringido a los gobernadores de primer término y la manipulación está restringida a las inversiones. Ha habido un cambio en la composición del gasto público hacia la inversión en períodos electorales en los estados cuyos gobernadores se encuentran en su primer mandato. Esta investigación contribuyó a la literatura nacional al identificar el mandato electoral como un factor capaz de influir en el gasto público estatal en períodos electorales.

Palabras Clave: Ciclos políticos presupuestarios, Mandatos electorales, Gastos públicos.

\section{INTRODUÇÃO}

A Teoria dos Ciclos Políticos tem origem na busca por relações entre economia, política e eleições e ajuda a explicar decisões tomadas por governantes durante o ciclo eleitoral. Downs (1957), um dos precursores da Teoria dos Ciclos Políticos, avaliou a hipótese de que os partidos formulam políticas públicas com o objetivo de ganhar votos. $\mathrm{O}$ autor parte da premissa de que os agentes públicos exercem sua função social como forma de obter fins privados, tais como renda, prestígio e poder. Nesse sentido, os governos negligenciam os efeitos das políticas públicas sobre a atividade econômica, exceto na medida em que influenciam as decisões dos eleitores.

Os primeiros modelos empíricos relacionados à Teoria dos Ciclos Políticos foram formulados a partir da década de 1970. Nordhaus (1975), baseado no trade-off entre inflação e desemprego (curva de Phillips), identificou que os governantes interferem na economia para reduzir o desemprego as vésperas das eleições e aplicam medidas corretivas após o pleito para reduzir o efeito inflacionário gerado pelas ações oportunistas. Esse ciclo é conhecido na literatura como Political Business Cycle.

Rogoff (1990) apresentou um modelo de ciclo político no qual a manipulação oportunista não ocorre em variáveis macroeconômicas e sim em variáveis fiscais facilmente perceptíveis pelos eleitores, capazes de sinalizar competência e aumentar a chance de sucesso do gestor nas eleições. Trata-se do Political Budget Cycle. Drazen (2001), após avaliar as pesquisas nos últimos 25 anos, contados a partir da pesquisa de Nordhaus (1975), concluiu que o Political Budget Cycle é mais consistente do ponto de vista teórico e empírico para captar ciclos políticos.

Baseado no modelo proposto por Rogoff (1990), diversas pesquisas internacionais (Alt \& Lassen, 2006; Brender \& Drazen, 2005; Haan, 2013; Klomp \& Haan, 2013; Rose, 2006; Saporitti \& Streb, 2008; Shi \& Svensson, 2006; Streb \& Torrens, 2013; Vergne, 2009) e nacionais (Arvate, Mendes \& Rocha, 2010; Queiroz, 2015; Sakurai, 2009; Sakurai \& Menezes, 2011; Vicente \& Nascimento, 2012) identificaram a presença de ciclos políticos em variáveis fiscais em diversos países, estados e municípios.

As pesquisas supracitadas ainda apontam diversos fatores condicionantes à ocorrência e intensidade dos ciclos político-orçamentários, tais como: anos de democracia, nível de desenvolvimento, qualidade institucional, eleitores informados, nível de transparência, presença de regras fiscais rígidas, questões políticopartidárias, entre outras.

Klein e Sakurai (2015) apontaram o mandato eleitoral como um fator capaz de influenciar a dinâmica do gasto público durante os ciclos políticos. Apesar do argumento de que os gestores, independente de estarem em primeiro ou segundo mandato, possuem incentivos para se comportar de forma oportunista, uma vez que pretendem manter seu grupo político no poder e consolidar suas carreiras políticas, Klein e Sakurai (2015) argumentam que a perspectiva de poder concorrer à reeleição aumenta o incentivo para o gestor distorcer a política fiscal, sobretudo em anos eleitorais, e agravar o ciclo político-orçamentário.

Nesse sentido, surge a seguinte questão de pesquisa: qual a influência do mandato eleitoral sobre os gastos públicos nos estados brasileiros? Com base nesse questionamento, o objetivo da pesquisa consiste em averiguar a influência do mandato eleitoral sobre os gastos públicos nos governos estaduais brasileiros. 
Para atingir tal objetivo, utilizou-se dados dos 26 estados brasileiros durante o período de 2003 a 2014, compreendendo três ciclos eleitorais.

A presente pesquisa diferencia-se dos estudos nacionais anteriores (Klein \& Sakurai, 2015; Nakaguma \& Bender, 2006, 2010) na medida em que utiliza proxies para o fator mandato eleitoral e os relaciona com os anos eleitorais. Dessa forma, pode-se verificar a influência do mandato eleitoral sobre os gastos públicos durante todo o mandato e, especificamente, no ano eleitoral.

Ao fornecer evidências de que o comportamento oportunista em anos eleitorais se restringe aos governadores que estão em primeiro mandato e que a manipulação se concentra nos gastos com investimentos, esta pesquisa contribui com a literatura sobre ciclos político-orçamentários ao identificar como a política fiscal dos estados brasileiros é influenciada pelo fator mandato eleitoral.

\section{REFERENCIAL TEÓRICO}

\subsection{Teoria dos Ciclos Políticos}

Baseado na ideia de que todo agente na divisão do trabalho exerce uma função social como meio de obter fins privados, Downs (1957) avaliou se os partidos políticos em uma democracia formulam políticas públicas estritamente como meio de ganhar votos, ou seja, se a função social de executar políticas públicas é realizada como um subproduto do interesse particular de obter renda, poder e prestígio. Considerando o cenário de conhecimento imperfeito e informação dispendiosa, Downs (1957) avaliou como três aspectos (persuasão, ideologia e irracionalidade) inerentes ao cenário proposto podem conduzir o gestor público a formular políticas públicas de acordo com seus interesses particulares.

Após avaliar a relação entre ciclos políticos e variações nas taxas de desemprego e inflação, Nordhaus (1975) introduziu na literatura o Political Business Cycle, considerado um dos primeiros modelos consistentes de ciclos políticos. O autor parte do pressuposto que os eleitores são ignorantes em relação ao trade-off entre inflação e desemprego e baseiam suas decisões de voto em experiências passadas. Além disso, o autor considera que os eleitores apresentam comportamento míope, ou seja, os acontecimentos mais recentes têm um peso maior na decisão de voto do que as informações mais antigas.

Nordhaus (1975) propõe que, com a aproximação das eleições, os candidatos governantes se sentirão tentados a manipular os instrumentos da política econômica a fim de estabelecer o cenário econômico ideal para conseguir suas reeleições ou a manutenção do seu partido no poder. Nesse sentido, o Political Business Cycle inicia-se com uma intervenção governamental no início do mandato eleitoral, aumentando o desemprego para reduzir taxas elevadas de inflação. Com a aproximação das eleições, o governo interfere na economia para reduzir a taxa de desemprego até um ponto ótimo, buscando melhorar seu desempenho eleitoral. Passadas as eleições e com níveis altos de inflação, o governo realiza novas intervenções aumentando o desemprego para combater a inflação, criando um ciclo político-econômico.

Hibbs (1977) introduziu o viés ideológico nos modelos de ciclos políticos, baseado na ideia de que os eleitores possuem uma ideologia partidária. $\mathrm{O}$ autor propôs um modelo para verificar se existiam diferenças partidárias na condução da política econômica e da implicação macroeconômica para os Estados Unidos e Inglaterra. As evidências revelaram que os partidos de orientação ideológica de direita dão maior ênfase ao combate à inflação, preocupando-se menos com a questão do desemprego, enquanto os partidos de orientação ideológica de esquerda possuem preferências contrárias.

Isso ocorre porque os partidos de direita representam os interesses da classe alta, ou seja, seus simpatizantes possuem a maior parte do capital financeiro e acumulam maiores perdas com a elevação da inflação. Já os partidos de esquerda representam indivíduos das classes trabalhadoras, mais sensíveis ao aumento do 
desemprego. Nesse sentido, os governantes priorizam a parcela da sociedade que forma sua base eleitoral no processo de elaboração e execução de políticas públicas (Hibbs, 1977).

Rogoff e Sibert (1988) apresentaram uma nova abordagem dos ciclos políticos e foram dois dos primeiros autores a apresentar a ideia na qual os instrumentos de política fiscal são utilizados para avaliar a competência do governante. Rogoff e Sibert (1988) enfatizaram ainda que a assimetria informacional existente entre gestor e eleitores proporciona ao político a possibilidade de distorcer a política fiscal pré-eleitoral de forma a aumentar sua probabilidade de reeleição. Tal distorção pode ocorrer tanto por meio do aumento de gastos que proporcionem grande visibilidade como por uma renúncia de receita tributária. Essa possibilidade de distorção deve-se à limitada capacidade de compreensão sobre as informações contidas nos relatórios orçamentários por parte dos eleitores.

Rogoff (1990) introduziu o primeiro modelo de ciclos políticos em variáveis fiscais (Political Budget Cycle). Baseado na assimetria informacional existente entre gestor público e eleitores, o ciclo proposto pelo autor baseia-se em modificações em variáveis fiscais nos períodos que antecedem as eleições. Tais alterações acontecem tanto nas despesas orçamentárias totais quanto na composição dos gastos públicos, dando preferência aos gastos capazes de sinalizar competência e aumentar a probabilidade de sucesso no pleito. Rogoff (1990) ressalta ainda que inovações institucionais podem amenizar a tendência de utilização oportunista e inapropriada de políticas fiscais.

Após avaliar as pesquisas sobre ciclos políticos nos últimos 25 anos, contados a partir da pesquisa de Nordhaus (1975), Drazen (2001) elaborou um modelo que considerou variáveis das políticas monetária e fiscal. As evidências revelaram que os modelos de manipulação da política fiscal se mostraram mais consistentes do ponto de vista teórico e empírico. Nesse sentido, as pesquisas recentes têm-se concentrado no estudo do Political Budget Cycle proposto por Rogoff (1990).

De modo geral, a literatura internacional aponta para a existência de manipulação fiscal, em países desenvolvidos, apenas na composição dos gastos públicos. Essa observação deve-se à postura de conservadorismo fiscal em relação às mensurações agregadas das despesas públicas em períodos eleitorais. Nesse sentido, a ocorrência de déficits fiscais ou aumento do endividamento em anos eleitorais reduz a probabilidade de recondução do grupo político do gestor público em países desenvolvidos (Brender, 2003; Brender \& Drazen, 2008; Peltzman, 1992).

Schneider (2010), após estudar a ocorrência de ciclos político-orçamentários nos estados da Alemanha Ocidental, afirma que não se deve analisar apenas se os governos usam uma tática fiscal em particular no período eleitoral, mas também investigar em quais condições esses governos estarão propensos a agirem dessa forma. Os resultados indicam que os governos evitam aumentar as despesas totais nos períodos que antecedem as eleições. Porém, existe um deslocamento da composição dos gastos públicos em direção aos gastos mais perceptíveis pelos eleitores.

Pesquisas internacionais (Drazen \& Eslava, 2010; Veiga \& Veiga, 2007b) apontam que a alteração na composição dos gastos públicos ocorre em direção aos investimentos, uma vez que consistem em gastos finais capazes de melhorar a imagem dos gestores. Veiga e Veiga (2007a), após estudarem municípios portugueses, identificaram que gastos mais elevados com investimentos estão associados a maiores porcentagens de votos obtidos pelos partidos políticos.

Drazen e Eslava (2010) avaliaram a influência das eleições sobre a dinâmica dos gastos públicos e a resposta dos eleitores às possíveis distorções oportunistas em municípios colombianos. As evidências revelaram que, no período que antecede às eleições, algumas despesas consideradas mais atrativas para os eleitores sofreram aumentos significativos. Tais componentes são gastos com infraestrutura, que inclui construções de rodovias e parques elétricos. Por outro lado, despesas de custeio sofreram reduções significativas. Constatouse também que os eleitores penalizam os partidos pela ocorrência de déficits nos períodos que antecedem as eleições e os recompensam pelo aumento de gastos considerados mais atrativos pelos eleitores. 
Diferentemente da postura de conservadorismo fiscal dos eleitores verificada em países desenvolvidos, as evidências nacionais indicam que os eleitores brasileiros recompensam tanto os gestores públicos que aumentam os gastos totais quanto aqueles que alteram a composição do orçamento em direção aos gastos mais perceptíveis pela sociedade (Arvate, Mendes \& Rocha, 2010; Klein, 2010; Queiroz, 2015; Sakurai, 2009; Sakurai \& Menezes, 2011; Vicente \& Nascimento, 2012).

Sakurai (2005), seguindo o raciocínio presente em Rogoff e Sibert (1988) e em Rogoff (1990), buscou evidências de ciclos orçamentários racionais nos municípios paulistas entre os anos de 1989 a 2001. Por meio de modelos de regressão, nos quais a variável de interesse é a dummy que indica se o ano é eleitoral, a pesquisa identificou impulsos positivos na despesa orçamentária em anos eleitorais.

Sakurai (2009) investigou a existência de ciclos eleitorais e partidários nas funções orçamentárias dos municípios brasileiros entre os anos de 1990 e 2005. Os resultados indicam que o fenômeno do ciclo eleitoral é observado mais expressivamente em algumas funções, como saúde, saneamento, assistência e previdência (variação aumentativa), habitação e urbanismo e transportes (variação diminutiva).

Sakurai e Menezes (2011) testaram a hipótese de modelos de ciclos oportunistas e partidários em 2.527 municípios brasileiros entre 1989 a 2005, utilizando dados de despesas, receitas e resultado orçamentário para testar a hipótese de que essas variáveis se comportam de forma diferente em função do ciclo eleitoral e da ideologia partidária dos prefeitos. Os resultados mostraram um aumento nos gastos totais e correntes e uma redução nos investimentos, nas receitas tributárias e no resultado orçamentário em anos eleitorais. Os autores também concluíram que a ideologia partidária exerce influência relativa sobre o desempenho das contas públicas locais.

Arvate, Mendes e Rocha (2010) avaliaram as eleições em 2.732 municípios brasileiros no ano de 2000 para verificar se os eleitores preferem um comportamento fiscal conservador ou expansionista no período eleitoral. As evidências revelaram que os eleitores brasileiros têm preferência por prefeitos que aumentam os gastos públicos nos períodos eleitorais. Sakurai e Menezes (2008), após análise de 2.235 municípios entre 1988 e 2000, identificaram que os gestores que apresentaram gastos per capita mais elevados ao longo dos mandatos tiveram mais chances de recondução.

Klein (2010) testou a presença de ciclos político-orçamentários nas eleições municipais do Brasil e checou se prefeitos que adotam tal política possuem maior probabilidade de reeleição. A amostra foi comporta por 5.406 municípios na eleição de 2004. As evidências apontaram que os prefeitos que aumentaram os gastos em anos eleitorais apresentaram maiores chances de reeleição, contanto que tal aumento seja feito dentro de limites aceitáveis pelos eleitores.

Vicente e Nascimento (2012) investigaram de que forma as manipulações fiscais com fins eleitorais, caracterizadas por indicadores obtidos das demonstrações contábeis do setor público, exercem influência na recondução de um governante e/ou de seus aliados políticos ao mesmo cargo no mandato seguinte. A amostra foi composta por 3.404 municípios abrangendo os mandatos de prefeitos findos em 2000, 2004 e 2008. As evidências revelaram que maiores gastos com investimentos elevam a probabilidade de recondução dos partidos políticos.

Queiroz (2015) avaliou a influência da composição dos gastos públicos sobre a probabilidade de recondução dos partidos políticos nas eleições municipais brasileiras de 2004, 2008 e 2012. As evidências revelaram que os municípios cujos partidos foram reconduzidos gastaram percentuais maiores da despesa orçamentária com investimentos e menores com pessoal e encargos sociais e outras despesas correntes. Modelos de regressão logística revelaram que os investimentos influenciaram positivamente as chances de recondução nas três eleições. 


\subsection{Aspectos Condicionantes}

As pesquisas sobre ciclos político-orçamentários apontam que a existência e magnitude dos ciclos podem ser influenciadas por diversos fatores condicionantes, entre eles: nível de desenvolvimento (Shi \& Svensson, 2006; Vergne, 2009), qualidade institucional e eleitores informados (Shi \& Svensson, 2006), transparência (Alt \& Lassen, 2006; Haan, 2013), regras fiscais (Rose, 2006; Streb \& Torrens, 2013), questões políticopartidárias (Saporitti \& Streb, 2008), anos de democracia (Brender \& Drazen, 2005; Haan, 2013; Klomp \& Haan, 2013), regimes fiscais centralizados ou descentralizados (Gonzalez, Hindriks \& Porteiro, 2013) e mandatos eleitorais (Klein \& Sakurai, 2015; Nakaguma \& Bender, 2010).

Shi e Svensson (2006) averiguaram como os ciclos políticos diferem entre os países. Os autores encontraram evidências que revelam que o tamanho dos ciclos políticos é consideravelmente superior nos países em desenvolvimento. As restrições institucionais presentes em países desenvolvidos impedem a expropriação dos recursos públicos para benefício particular por parte dos funcionários públicos e políticos. Além disso, a participação significativa de eleitores informados presente nesses países restringe manipulações fiscais em períodos eleitorais (Shi \& Svensson, 2006). Os autores concluem que diferenças institucionais podem explicar, em grande parte, variações no tamanho dos ciclos políticos quando se compara países desenvolvidos e em desenvolvimento.

Segundo Vergne (2009), a dimensão dos ciclos políticos é influenciada pela quantidade de recursos econômicos e políticos do país. Os resultados revelam que os países em desenvolvimento, com eleições competitivas e mais recursos naturais de produção possuem ciclos políticos maiores. A pesquisa reafirmou os resultados de Shi e Svensson (2006), apontando que quanto mais eleitores informados e quanto maior o nível de descentralização, menor a quantidade de distorções e manipulação na alocação dos gastos públicos em anos eleitorais.

Haan (2013) afirma que o ciclo político orçamentário é mais provável de ocorrer e mais intenso em democracias mais jovens do que nas democracias estabelecidas. Para Brender e Drazen (2005) a manipulação fiscal é usada mais amplamente em novas democracias porque os eleitores são inexperientes com a política eleitoral ou simplesmente não possuem as informações necessárias para avaliar a manipulação fiscal. Assim, a diferença informacional existente entre os dois tipos de democracia influencia na ocorrência e magnitude da manipulação fiscal.

Avaliando o nível de transparência, Alt e Lassen (2006) estudaram o nível de conhecimento sobre as táticas fiscais do governo, suas ações e implicações nas políticas públicas que estão à disposição da população, da mídia e dos mercados financeiros. Os autores encontraram evidências que apontam para a existência de ciclos políticos em países com baixa transparência. Além disso, o modelo também mostra que a mídia controlada pelo Estado avigora a ausência de transparência.

Rose (2006) afirma que a magnitude da manipulação política das contas públicas é determinada pelo contexto institucional da formação do processo orçamentário. Utilizando dados em painel dos estados norteamericanos, Rose (2006) concluiu que regras fiscais mais rígidas dificultam a ocorrência de manipulações oportunistas.

Streb e Torrens (2013) elaboraram um modelo baseado no papel dos agentes de veto legislativos como uma possível solução para os ciclos políticos. Os resultados encontrados apontaram que as regras não são suficientes para evitar os ciclos políticos, afirmando que, para o poder de veto ser eficaz, o legislador deve ter a capacidade de supervisão e fiscalização, assegurando que o chefe do poder executivo está em conformidade com a lei do orçamento aprovada.

Gonzalez, Hindriks e Porteiro (2013) avaliaram a probabilidade de distorção nas políticas fiscais em períodos eleitorais em sistemas centralizados e descentralizados. Os resultados encontrados confirmam que, no sistema centralizado, os impactos que afetam a probabilidade dos ciclos políticos são a possibilidade de distorção seletiva e a diversificação do custo. Os resultados indicam que a probabilidade de ocorrência 
de ciclos político-orçamentários é menor no sistema centralizado quando comparada à configuração descentralizada, adotada pelo Brasil.

\subsection{Hipótese de Pesquisa}

Dentre os aspectos condicionantes para a existência e magnitude dos ciclos político-orçamentários descritos pela literatura, essa pesquisa concentra-se no fator mandato eleitoral. Parte-se do pressuposto de que os gestores aptos a concorrer à reeleição possuem maiores incentivos para distorcer a política fiscal.

Nakaguma e Bender (2010) investigaram os efeitos da Emenda Constitucional 16/1997 (Emenda da Reeleição) sobre os gastos públicos nos estados brasileiros durante o período de 1986 a 2004. Para tanto, os autores utilizaram uma variável dummy que assume o valor igual a 1, caso o governador tenha se candidatado à reeleição. Os resultados indicaram que a Emenda da Reeleição implicou em um aumento na amplitude dos ciclos na receita total, receita corrente e transferências correntes. Avaliando as despesas, os resultados indicaram que governantes candidatos à reeleição elevaram a despesa total, corrente e de custeio acima dos governantes não candidatos à reeleição.

Klein e Sakurai (2015) propuseram o mandato eleitoral como um fator determinante para a ocorrência dos ciclos político-orçamentários. Foram analisados 3.393 municípios brasileiros entre 2001 e 2008. Os resultados indicaram diferenças fiscais significativas entre os prefeitos que estão no primeiro e segundo mandato. No ano eleitoral, os prefeitos que estão no primeiro mandato alteram a composição da despesa pública em direção aos gastos de capital, especialmente os investimentos, e reduzem as despesas correntes.

Baseado nessas evidências, esperava-se que o mandato eleitoral influenciasse de forma significativa a dinâmica das despesas públicas nos estados brasileiros. Nesse sentido, a seguinte hipótese de pesquisa foi formulada:

H1: O mandato eleitoral exerce influência sobre os gastos públicos dos estados brasileiros.

Diferentes categorias de despesas possuem efeitos diferenciados sobre a votação, com o partido político que está no poder beneficiando-se com despesas seletivas. Pesquisas internacionais (Drazen \& Eslava, 2010; Veiga \& Veiga, 2007b) e nacionais (Klein \& Sakurai, 2015; Queiroz, 2015; Vicente \& Nascimento, 2012) identificaram que a manipulação oportunista se concentra nos investimentos. Além disso, identificou-se uma relação positiva entre os investimentos e o desempenho eleitoral dos gestores públicos.

Em resumo, baseado no pressuposto teórico de que os governadores aptos a concorrer à reeleição possuem mais incentivos para distorcer a política fiscal estadual, espera-se que os gestores que exercem o primeiro mandato alterem a composição do orçamento em direção aos gastos mais perceptíveis pela sociedade, especificamente os investimentos. Para viabilizar esse aumento nos investimentos em anos eleitorais, esperase uma redução nos gastos correntes dos estados brasileiros cujos gestores estão em primeiro mandato.

\section{Procedimentos Metodológicos}

\subsection{Amostra da Pesquisa}

O objeto de estudo desta pesquisa consiste nos estados brasileiros. Justifica-se essa escolha por dois motivos.: Inicialmente, o acesso às informações sobre as eleições e aos dados detalhados sobre os gastos estaduais foram confirmados. Em segundo lugar, justifica-se essa escolha em função do ineditismo da relação entre mandatos eleitorais e ciclos político-orçamentários nesses entes governamentais. A amostra da pesquisa consiste nos 26 estados da federação nos anos de 2003 a 2014, compreendendo 312 observações e três ciclos eleitorais. 
O processo de coleta dos dados ocorreu exclusivamente pela internet nos meses de novembro e dezembro de 2015. As informações eleitorais foram coletadas diretamente do sítio do Tribunal Superior Eleitoral (TSE). Coletaram-se as informações sobre gastos públicos no banco de dados Sistema de Informações Contábeis e Fiscais do Setor Público Brasileiro (Siconfi). Por fim, a população dos estados foi coletada no sítio do Instituto Brasileiro de Geografia e Estatística (IBGE).

\subsection{Definição das Variáveis}

As variáveis dependentes consistem nos gastos públicos estaduais. Inicialmente, foram estudadas as categorias econômicas das despesas públicas: despesas correntes e de capital. Posteriormente, a análise aprofundou o estudo até o nível da natureza da despesa pública. Essa classificação busca identificar o fato gerador que ocasionou a saída de recursos da organização pública. Esse aprofundamento baseia-se em pesquisas (Drazen \& Eslava, 2010; Schneider, 2010; Veiga \& Veiga, 2007b) que indicam que os ciclos políticos também existem na composição dos gastos públicos, favorecendo gastos facilmente perceptíveis pelos eleitores e capazes de sinalizar competência do gestor público.

A Portaria Interministerial MF/MPOG n ${ }^{\circ}$ 163/2001 classifica a natureza da despesa em seis grupos: a) pessoal e encargos sociais, b) juros e encargos da dívida, c) outras despesas correntes, d) investimentos, e) inversões financeiras e f) amortização da dívida. Ressalta-se que os grupos b e f foram excluídos da análise por não consistirem em despesas passíveis de manipulação pelos gestores públicos. Drazen e Eslava (2010) explicam que as despesas relacionadas ao serviço da dívida são consideradas como fora do controle dos gestores públicos.

Em resumo, a pesquisa verificou a influência do fator mandato eleitoral sobre seis tipos de despesas públicas, conforme Tabela 1.

Tabela 1 Variáveis dependentes

\begin{tabular}{ll}
\hline Nomenclatura & Gasto Público \\
\hline COR & Despesa corrente \\
CAP & Despesa de capital \\
PES & Pessoal e encargos \\
ODC & Sociais \\
& Outras despesas \\
& Correntes
\end{tabular}

Fonte: Elaboração própria.

Esta pesquisa utilizou a despesa empenhada com base no artigo 35 da Lei no 4.320/1964, que considera pertencentes aos exercícios as despesas neles legalmente empenhadas. Para eliminar o efeito escala, os gastos públicos foram controlados pela despesa orçamentária total, ou seja, as variáveis representam um percentual dos gastos totais dos estados.

As variáveis independentes de interesse buscam capturar o efeito do mandato do governador sobre os gastos públicos. A Tabela 2 apresenta as três variáveis de interesse da pesquisa. 
Tabela 2 Descrição da variável independente de interesse

\begin{tabular}{|c|c|c|}
\hline Variável & Classificação & Descrição \\
\hline \multirow{2}{*}{ PM } & 1 & Governador do estado exerce o primeiro mandato. \\
\hline & 0 & Governador do estado exerce o segundo mandato. \\
\hline \multirow[b]{2}{*}{ PMAE } & 1 & Governador do estado exerce o primeiro mandato e o ano é eleitoral. \\
\hline & 0 & $\begin{array}{l}\text { Governador do estado não exerce o primeiro mandato ou não é ano } \\
\text { eleitoral. }\end{array}$ \\
\hline & 1 & Governador do estado exerce o segundo mandato e o ano é eleitoral. \\
\hline
\end{tabular}

Fonte: Elaboração própria.

A variável Primeiro Mandato (PM) busca capturar o efeito do primeiro mandato sobre os gastos públicos, desprezando o fator ano eleitoral. Nesse sentido, se o governador exerce o primeiro mandato foi atribuído o valor 1 para os quatro anos de mandato do gestor. Caso contrário, atribuiu-se o valor 0 aos quatro anos.

A variável Primeiro Mandato e Ano Eleitoral (PMAE) busca verificar a influência da situação na qual o gestor está no primeiro mandato e o ano é eleitoral sobre os gastos públicos. Essa variável recebeu o valor 1 se, e somente se, o governador estiver em primeiro mandato e em ano eleitoral. Para todas as demais situações, atribuiu-se o valor 0 .

Por fim, a variável Segundo Mandato e Ano Eleitoral (SMAE) verifica a influência da situação na qual o governador está no segundo mandato e o ano é eleitoral sobre os gastos públicos. De forma análoga à anterior, essa variável recebeu o valor 1 se, e somente se, o governador estiver em segundo mandato e em ano eleitoral. Caso contrário, atribuiu-se o valor 0 .

Tradicionalmente, as pesquisas (Brender \& Drazen, 2013; Drazen \& Eslava, 2010; Katsimi \& Sarantides, 2012; Sakurai, 2005, 2009; Sakurai \& Menezes, 2011; Vergne, 2009) que verificam a influência do ano eleitoral sobre os gastos públicos utilizam modelos de regressão linear com uma variável dummy representando o ano eleitoral como variável independente. Essa pesquisa desmembrou essa variável dummy em duas (PMAE e SMAE), de forma a verificar qual a influência do mandato eleitoral nos anos eleitorais sobre os gastos públicos.

A utilização de três variáveis para capturar o efeito mandato eleitoral possibilita uma análise mais consistente sobre a influência desse fator sobre os gastos públicos. Nakaguma e Bender (2010) utilizaram uma variável dummy que assume o valor 1, caso o governador tenha se candidatado à reeleição e 0 caso contrário. Já Klein e Sakurai (2015) utilizaram duas variáveis, que equivalem às variáveis PM e PMAE utilizadas pela presente pesquisa.

Além das variáveis de interesse, pesquisas nacionais (Arvate, Mendes \& Rocha, 2010; Sakurai, 2009; Sakurai \& Menezes, 2011; Vicente \& Nascimento, 2012) revelam uma série de fatores capazes de influenciar os gastos públicos. A Tabela 3 revela as variáveis de controle utilizadas por essa pesquisa.

Tabela 3 Variáveis de controle

\begin{tabular}{ll}
\hline Nomenclatura & Descrição da variável \\
\hline ESQ & Dummy que indica se o partido político do governador é de esquerda. \\
DIR & Dummy que indica se o partido político do governador é de direita. \\
PRE & Dummy que indica se o partido do governador pertence à coligação do \\
& Presidente. \\
POP & Logaritmo natural da população. \\
PCE & Dummy correspondente ao primeiro ciclo eleitoral (2003, 2004, 2005 e 2006)
\end{tabular}

Fonte: Elaboração própria. 
As variáveis ESQ e DIR revelam a influência do viés ideológico dos partidos dos governadores sobre os gastos públicos estaduais. Utilizou-se o critério adotado por pesquisas passadas (Klein \& Sakurai, 2015; Sakurai, 2009; Sakurai \& Menezes, 2011) para definir o viés ideológico dos partidos. Os partidos PMDB, PSDB e PTB foram considerados de centro e utilizados como categoria de referência. Nesse sentido, fizeramse as interpretações das variáveis ESQ e DIR tomando como referência os partidos de centro. Os seguintes partidos foram considerados de esquerda: PT, PSB, PPS, PDT e PMN. Já os partidos PFL, PP e DEM foram considerados de direita.

A variável PRE busca capturar a influência política do presidente sobre os gastos estaduais. Nesse sentido, se o partido do governador fez parte da coligação que elegeu o presidente da República, atribui-se o valor 1. Caso contrário, o valor 0 foi atribuído ao longo do mandato do governador. Por fim, a variável POP busca capturar influências demográficas sobre os gastos públicos. Para tanto, utilizou-se o logaritmo natural da população dos estados brasileiros.

Para capturar o efeito temporal sobre a variação dos gastos públicos, variáveis binárias foram inseridas no modelo. O último ciclo eleitoral foi tomado como referência pelo fato de ser o mais recente. A variável Primeiro Ciclo Eleitoral (PCE) recebeu o valor 1 para os anos de 2003, 2004, 2005 e 2006 e o valor 0 para os demais. Já a variável Segundo Ciclo Eleitoral (SCE) recebeu o valor 1 para os anos de 2007, 2008, 2009 e 2010 e o valor 0 para os demais.

\subsection{Modelo Econométrico}

Para verificar a influência das variáveis independentes sobre os gastos públicos, utilizou-se a técnica de regressão com dados em painel, uma vez que a amostra contempla dados seccionais (estados) e temporais (anos). Os gastos públicos foram modelados em função do fator Mandato Eleitoral. A Equação 1 apresenta o modelo utilizado para verificar a influência do mandato eleitoral sobre os gastos públicos dos estados brasileiros.

$$
G P_{i t}=\beta_{0}+\beta_{1} P M_{i t}+\beta_{2} P M A E_{i t}+\beta_{3} S M A E_{i t}+\beta_{4} V C_{i t}+\varepsilon_{i t}
$$

Onde:

$V F_{i t}=$ Gasto público do estado $\underline{\underline{i}}$, no ano $t$;

$P M_{i t}=$ Governador exerce o primeiro mandato;

$P M A E_{i t}=$ Governador exerce o primeiro mandato e o ano é eleitoral;

$S M A E_{i t}=$ Governador exerce o segundo mandato e o ano é eleitotal;

$V C_{i t}=$ Conjunto de variáveis de controle, conforme Tabela 3;

$\varepsilon_{i t}=$ Termo de erro.

\section{Apresentação e Discussão dos Resultados}

\subsection{Apresentação dos Dados}

As variáveis de interesse dessa pesquisa relacionam-se ao fator mandato eleitoral. Nos 26 estados brasileiros, 20, 13 e 18 governadores elegeram-se para o primeiro mandato nas eleições de 2006, 2010 e 2014, respectivamente, totalizando 51 das 78 disputas do período. A Tabela 4 apresenta a diferença de comportamento dos gastos nos governos cujos gestores estão em primeiro e segundo mandato. 
Tabela 4 Comportamento dos gastos nos mandatos

\begin{tabular}{|c|c|c|c|c|c|c|c|}
\hline \multirow{3}{*}{ Variáveis } & \multicolumn{3}{|l|}{ Primeiro Mandato } & \multicolumn{3}{|l|}{ Segundo Mandato } & \multirow{3}{*}{$\begin{array}{l}\text { Primeiro x Segundo } \\
\text { Mandato (MW) ( } \mathrm{p} \text {-valor) }\end{array}$} \\
\hline & $\begin{array}{l}\text { Anos năo Eleitorais } \\
(\%)\end{array}$ & Ano Eleitoral $\left(\varphi_{0}\right)$ & $\begin{array}{l}\text { Alteraçăo do ano } \\
\text { eleitoralt }\end{array}$ & $\begin{array}{l}\text { Anos năo Eleitorais } \\
\left(\varphi_{0}\right)\end{array}$ & Ano Eleitoral $(\%)$ & $\begin{array}{l}\text { Alteraçăo do ano } \\
\text { eleitoralt }\end{array}$ & \\
\hline & (A) & (B) & (B) - (A) & (C) & (D) & (D) - (C) & \\
\hline & 85,56 & 84,56 & $-1,00^{* *}$ & 84,67 & 84,56 & $-0,11$ & 0,071 \\
\hline CAP & 14,44 & 15,44 & $1,00 * *$ & 15,33 & 15,44 & 0,11 & 0,071 \\
\hline & 46,01 & & $-1,35^{*}$ & 43,61 & 44,93 & $1,32^{*}$ & 0,033 \\
\hline ODC & $\begin{array}{l}46,01 \\
36,27\end{array}$ & $\begin{array}{l}4,66 \\
37,02\end{array}$ & $\begin{array}{l}-1,35^{n} \\
0,75\end{array}$ & $\begin{array}{l}4,61 \\
37,96\end{array}$ & $\begin{array}{l}4,93 \\
36,75\end{array}$ & $\begin{array}{l}1,32^{*} \\
-1,21^{*}\end{array}$ & $\begin{array}{l}0,069 \\
0,069\end{array}$ \\
\hline INV & 8,22 & 10,51 & $2,29 * * *$ & 9,86 & 10,60 & 0,74 & 0,005 \\
\hline IVF & 1,83 & 1,51 & $\begin{array}{l}-0,33^{* *} \\
-\end{array}$ & 1,86 & 1,45 & $\begin{array}{l}-0,41 \\
\end{array}$ & 0,900 \\
\hline Estados & $51(65,38 \%)$ & & & $27(34,62 \%)$ & & & 78 \\
\hline
\end{tabular}

Fonte: Elaboração Própria.

O símbolo + significa que os valores dessa coluna foram submetidos ao teste de Wilcoxon.

Os símbolos ${ }^{*},{ }^{* *} \mathrm{e}^{* * *}$ representam significância estatística a $10 \%, 5 \%$ e $1 \%$, respectivamente.

Inicialmente, destaca-se que os valores que constam na coluna dos anos não eleitorais consistem na média dos três primeiros anos de mandato. Observa-se que, independente do mandato, os governadores reduzem as despesas correntes e aumentam as de capital nos anos eleitorais. Porém, a intensidade da variação nos gastos difere entre as duas situações. Enquanto a variação das categorias econômicas dos governadores que estão no primeiro mandado foi de $1 \%$, a variação dos gestores que estão no segundo mandato foi de apenas $0,11 \%$. Os testes de Wilcoxon confirmam que as médias dos períodos sem e com efeito eleitoral diferem estatisticamente apenas nos governos cujos gestores estão em primeiro mandato.

Esse resultado corrobora a pesquisa de Klein e Sakurai (2015), que, após analisar 3.393 municípios brasileiros entre 2001 e 2008, identificou que os prefeitos em primeiro mandato reduziram as despesas correntes de forma mais significativa do que os que estavam no segundo mandato. Essas evidências revelam que, tanto no nível municipal quanto no estadual, existe uma alteração na composição dos gastos públicos em direção às despesas de capital nos anos eleitorais de forma mais significativa nos governos cujos gestores estão em primeiro mandato em relação aos que estão em segundo mandato.

Estendendo a análise para a natureza do gasto público, percebe-se que a direção das variações difere para os gastos com pessoal e outras despesas correntes. Já os investimentos e as inversões financeiras apresentaram a mesma direção nas variações. As direções das variações obtidas para os gastos com pessoal e investimentos coincidem com os achados de Klein e Sakurai (2015) nos municípios brasileiros. Os autores não testaram as outras despesas correntes e as inversões financeiras.

Percebe-se que tanto os governadores que estavam em primeiro quanto em segundo mandato aumentaram os gastos com investimento no ano eleitoral. Porém, o aumento nos estados cujos governadores estavam em primeiro mandato foi da ordem de 2,29 pontos percentuais, enquanto nos estados cujos governadores estavam em segundo mandato, o aumento foi da ordem de 0,74 pontos percentuais. Essa diferença deve-se ao fato de os gastos com investimentos serem os mais perceptíveis pela população (Drazen \& Eslava, 2010; Queiroz, 2015; Veiga \& Veiga, 2007b; Vicente \& Nascimento, 2012) e capazes de aumentar a probabilidade de reeleição dos gestores públicos.

Por fim, o teste de Mann-Whitney compara as variações dos gastos dos governos cujos gestores estão em primeiro e segundo mandato. Exceto pelas inversões financeiras, todas as demais médias das variações diferem estatisticamente ao nível de $10 \%$. Essa evidência reforça a expectativa teórica da pesquisa na medida em que se verifica que a dinâmica das variações dos gastos difere entre os governos cujos gestores estão em primeiro e segundo mandato.

Para avaliar como o fator mandato altera a dinâmica do gasto público no ano eleitoral, a Tabela 5 apresenta as médias de cada um dos gastos públicos de acordo com o mandato e o efeito eleitoral. Ressalta-se que cada variável é composta por 312 observações, consequência da análise de 26 estados ao longo de 12 anos. Os valores constantes na Tabela 5 foram obtidos pela média das observações que se enquadram na situação descrita. 
Tabela 5 Efeito Mandato sobre os gastos públicos

\begin{tabular}{|c|c|c|c|c|c|c|c|c|c|}
\hline \multirow{2}{*}{ Variáveis } & \multicolumn{3}{|c|}{ Efeito mandato $(\%)$} & \multicolumn{3}{|c|}{$\begin{array}{l}\text { Primeiro Mandato e ano } \\
\text { eleitoral (\%) }\end{array}$} & \multicolumn{3}{|c|}{$\begin{array}{l}\text { Segundo Mandato e ano eleitoral } \\
\text { (\%) }\end{array}$} \\
\hline & PriMand & SegMand & MW & PMAE & Outros & MW & SMAE & Outros & MW \\
\hline $\mathrm{COR}$ & 85,31 & 84,64 & 0,244 & 84,56 & 85.18 & 0.189 & 84.56 & 85,13 & 0.789 \\
\hline $\mathrm{CAP}$ & 14,69 & 15,36 & 0,244 & 15,44 & 14,82 & 0,189 & 15,44 & 14,87 & 0,789 \\
\hline PES & 45,67 & 43,94 & 0,034 & 44,66 & 45,15 & 0,683 & 44,93 & 45,09 & 0,770 \\
\hline ODC & 36,46 & 37,66 & 0,020 & 37,02 & 36,85 & 0,833 & 36,75 & 36,89 & 0,960 \\
\hline INV & 8,80 & 10,05 & 0,001 & 10,51 & 8,98 & 0,006 & 10,60 & 9,10 & 0,077 \\
\hline IVF & 1,75 & 1,76 & 0,273 & 1,51 & 1,80 & 0,934 & 1,45 & 1,78 & 0,489 \\
\hline Estados & $204+$ & $108 \times$ & 312 & 51 & 261 & 312 & 27 & 285 & 312 \\
\hline
\end{tabular}

Fonte: Elaboração Própria.

+ O número de 204 estados foi obtido mediante a multiplicação de 51 governadores em primeiro mandato por 4 anos de gestão. × O número de 108 estados foi obtido mediante a multiplicação de 27 governadores em segundo mandato por 4 anos de gestão.

Avaliando apenas o fator mandato, percebe-se que os governos cujos gestores estão em primeiro mandato gastaram um percentual maior da despesa orçamentária com despesa corrente em relação aos governos cujos gestores estão em segundo mandato. Porém, o teste de Mann-Whitney comprova que as médias não diferem estatisticamente ao nível de $5 \%$.

Avaliando a natureza dos gastos, percebe-se que os governadores em primeiro mandato aplicam um percentual maior da despesa orçamentária com pessoal e menor com outras despesas correntes, investimentos e inversão financeira em relação aos governadores que estão no segundo mandato. Os testes de MannWhitney mostram que a médias diferem estatisticamente para os gastos com pessoal, ODC e investimento.

Percebe-se que, desconsiderando o ano eleitoral, os governadores em primeiro mandato gastaram um percentual maior da despesa orçamentária com despesas correntes, sobretudo com pessoal e encargos sociais, em relação aos governadores em segundo mandato. Porém, ao considerar os fatores primeiro mandato e ano eleitoral de maneira conjunta, a composição dos gastos públicos apresenta-se de forma oposta, com percentuais maiores da despesa orçamentária gastos com despesas de capital.

Os estados cujos governadores estão em primeiro mandato e o ano é eleitoral (PMAE) gastaram 84,56\% da despesa orçamentária com despesas correntes, enquanto os outros estados gastaram 85,25\%. Apesar da diferença, o teste de Mann-Whitney confirma que as médias não diferem estatisticamente ao nível de 5\%. Ao avaliar a natureza dos gastos, percebe-se que os estados PMAE gastaram menos com pessoal e inversões financeiras e mais com outras despesas correntes e investimento em relação aos outros estados. Os testes de Mann-Whitney revelam que apenas nos gastos com investimento, as médias dos estados PMAE e dos outros diferem estatisticamente ao nível de 5\%.

Por fim, os estados cujos governadores estão em segundo mandato gastaram um percentual maior das despesas orçamentárias com investimentos. Porém, diferentemente das evidências obtidas para os estados PMAE, as médias dos gastos dos estados SMAE não diferem estatisticamente ao nível de $5 \%$ dos demais estados.

A análise conjunta das Tabelas 4 e 5 indica uma alteração mais significativa da composição dos gastos públicos em direção aos investimentos nos anos eleitorais apenas nos estados cujos governadores estão em primeiro mandato. Essa evidência sugere que as variáveis PM e PMAE exercem influência negativa e positiva, respectivamente, sobre os investimentos, indicando um deslocamento da composição da despesa pública nos anos eleitorais em direção aos investimentos, conforme expectativa teórica dessa pesquisa. 


\subsection{Influência do Mandato Eleitoral sobre os Gastos Públicos}

Para testar se as variáveis PM e PMAE exercem influência negativa e positiva, respectivamente, sobre os investimentos, regressões com dados em painel foram estimadas por meio da Equação 1. A Tabela 6 apresenta os parâmetros estimados e as estatísticas referentes a cada um dos seis modelos elaborados.

Ressalta-se que, na ausência de elementos teóricos que indiquem a utilização de um tipo específico de painel, essa pesquisa utilizou os testes de Chow, Breusch-Pagan e Hausman para determinar o tipo mais adequado de painel para o conjunto de dados. O teste Variance Inflation Factor (VIF) foi executado e não indicou problemas de multicolinearidade entre as variáveis do modelo.

Tabela 6 Influência dos mandatos eleitorais sobre os gastos públicos

\begin{tabular}{lllllll}
\hline Variáveis & CORx & CAPx & PESx & ODC+ & INVx & IVF+ \\
\hline Constante & $50,3087^{* * *}$ & $49,6913^{* * *}$ & $60,1450^{* * *}$ & $466,898^{*}$ & $39,1528^{* * *}$ & $-178,543$ \\
PM & 0,4443 & $-0,4443$ & $1,4662^{*}$ & $-0,8926$ & $-1,3727^{* * *}$ & 0,2479 \\
PMAE & $-1,0596^{*}$ & $1,0596^{*}$ & $-1,3292$ & $1,4782^{* *}$ & $2,3356^{* * *}$ & $-0,6297^{* *}$ \\
SMAE & $-0,1649$ & 0,1649 & 1,3487 & $-0,4785$ & 0,7867 & $-0,7088^{* *}$ \\
ESQ & 0,7163 & $-0,7163$ & 0,7276 & $-0,1552$ & 0,5060 & $-0,0855$ \\
DIR & $-1,2131$ & 1,2131 & 1,5666 & $-2,5076$ & $1,8900^{* *}$ & $-0,1798$ \\
PRE & 0,8518 & $-0,8518$ & $-0,1113$ & 0,7225 & $-0,0121$ & $-0,2341$ \\
POP & $2,2198^{* * *}$ & $-2,2198^{* * *}$ & $-0,9181$ & $-28,1502$ & $-1,9394^{* * *}$ & 11,7707 \\
PCE & $1,0749^{* *}$ & $-1,0749^{* *}$ & $-2,8892^{* * *}$ & $-0,7604$ & $-0,9467^{* *}$ & $1,1837^{*}$ \\
SCE & $-0,3323$ & 0,3323 & $-4,0538^{* * *}$ & 1,9225 & 0,2543 & $0,7228^{* *}$ \\
\hline R2 within & 0,0458 & 0,0458 & 0,1231 & 0,1453 & 0,1281 & 0,0580 \\
R2 between & 0,3260 & 0,3260 & 0,0919 & 0,2112 & 0,3071 & 0,0116 \\
Wald chi2 (9) & $23,5254^{* * *}$ & $23,5254^{* * *}$ & $40,8774^{* * *}$ & - & $50,7629^{* * *}$ & - \\
Teste F & - & - & - & $2,6366^{* *}$ & - & 1,1878 \\
Jarque -Bera & $93,4459^{* * *}$ & $93,4459^{* * *}$ & $5,1684^{*}$ & 0,1227 & $427,509^{* * *}$ & $2.020,09^{* * *}$ \\
Wald & - & - & - & $1.011,14^{* * *}$ & - & $39.972,4^{* * *}$ \\
Wooldridge & - & - & - & $56,254^{* * *}$ & - & 0,616 \\
\hline
\end{tabular}

Fonte: Elaboração própria.

$\mathrm{O}$ símbolo $\times$ significa que o modelo de painel com efeitos aleatórios foi adotado. $\mathrm{O}$ símbolo + significa que o modelo de painel com efeitos fixos foi adotado. Para ambas as variáveis (ODC e IVF), os erros-padrão foram estimados pela técnica de Newey-West. Os símbolos ${ }^{*},{ }^{* *} \mathrm{e}^{* * *}$ representam significância estatística a $10 \%, 5 \%$ e 1\%, respectivamente.

Avaliando inicialmente as categorias econômicas, ressalta-se que as despesas correntes e de capital apresentam uma correlação negativa perfeita, uma vez que a soma das duas variáveis corresponde exatamente à despesa orçamentária. Esse fator justifica a inversão dos sinais dos parâmetros estimados.

A variável PM apresentou uma relação negativa e significativa ao nível de 5\% apenas para os investimentos. Isso significa que os governadores que estavam no primeiro mandato gastaram um percentual menor da despesa orçamentária com investimentos.

A variável PMAE apresentou influência significativa sobre os gastos correntes apenas ao nível de 10\% de significância. Essa evidência se aproxima dos achados de Klein e Sakurai (2015), que identificaram uma relação negativa e significativa (ao nível de $5 \%$ de significância) entre a variável PMAE e os gastos correntes nos municípios brasileiros. Ressalta-se que Klein e Sakurai (2015) utilizaram gastos per capita em valores correntes de 2008, enquanto a presente pesquisa padronizou as variáveis pela despesa orçamentária, não necessitando de correção monetária dos valores.

Aprofundando o estudo e passando a avaliar a natureza dos gastos públicos, a variável PMAE apresentou relação significativa com as outras despesas correntes, investimentos e inversão financeira. Esse achado indica que os gestores que estão em primeiro mandato e em ano eleitoral gastam um percentual maior da despesa orçamentária com outras despesas correntes, investimentos e menor com inversão financeira. 
Por fim, a variável SMAE apresentou influência significativa apenas com o grupo inversão financeira. Essa evidência sugere que, independente de exercer o primeiro ou segundo mandato, o governador reduz os gastos com inversão financeira no ano eleitoral, conforme apresentado na Tabela 5 por meio da estatística descritiva.

Diante dessas evidências, pode-se destacar que a hipótese de pesquisa de que o mandato eleitoral exerce influência sobre os gastos públicos dos estados brasileiros foi validada apenas para alguns tipos de despesas, uma vez que relações significativas para a variável PMAE foram obtidas apenas para alguns grupos de despesas.

Percebe-se também que o comportamento oportunista dos gestores que estão em primeiro mandato se concentra nos investimentos, uma vez que se verificou uma relação negativa e significativa com a variável PM e positiva e significativa com a variável PMAE. Essa evidência revela uma clara modificação na composição dos gastos públicos em direção aos investimentos nos anos eleitorais nos estados cujos gestores estão em primeiro mandato. Em resumo, os governadores em primeiro mandato gastam um percentual menor da despesa orçamentária com investimentos nos anos sem efeito eleitoral e aumentam significativamente esses gastos nos anos eleitorais.

Esse resultado é consistente com estudos internacionais (Drazen \& Eslava, 2010; Veiga \& Veiga, 2007a) e nacionais (Queiroz, 2015; Vicente \& Nascimento, 2012), que indicam que gastos maiores com investimentos aumentam a probabilidade de recondução ao cargo de gestor público. Nesse sentido, aumentar os investimentos nos anos eleitorais faz sentido, uma vez que consiste na despesa mais perceptível pela sociedade.

O teste Jarque-Bera revela que, com exceção das outras despesas correntes, os resíduos dos modelos não apresentaram distribuição normal. Porém, baseado no Teorema Central do Limite, pode-se relaxar esse pressuposto, uma vez que, para grandes amostras, os termos de erro tendem a se distribuírem normalmente (Brooks, 2014).

Os testes de ajustamento dos modelos revelaram um baixo nível de aderência do modelo aos dados. Essa constatação foi considerada natural, uma vez que existem diversos outros fatores capazes de influenciar a dinâmica dos gastos públicos. Por fim, os testes de Wald e Wooldridge indicaram presença de heterocedasticidade e autocorrelação, respectivamente, nos modelos com efeitos fixos elaborados. Para ajustar, adotou-se o método de correção de Newey-West.

As demais variáveis de controle fornecem informações adicionais sobre a dinâmica dos gastos públicos estaduais. As variáveis de ideologia política dos governadores revelam que os partidos de direita gastam mais com investimentos em relação aos partidos de centro. A variável que indica alinhamento político com o presidente da República não exerceu influência sobre nenhum dos gastos públicos. A variável População indicou uma relação positiva sobre as despesas correntes. Avaliando a natureza dos gastos, o logaritmo natural da população influenciou negativamente os investimentos. Por fim, as variáveis correspondentes aos ciclos eleitorais indicam modificações na composição da despesa orçamentária ao longo dos três ciclos eleitorais, com um aumento dos gastos com pessoal e uma redução das inversões financeiras ao longo do período.

\section{Considerações Finais}

O objetivo da pesquisa consistiu em verificar a influência do mandato eleitoral sobre os gastos públicos dos governos estaduais brasileiros. A amostra foi composta pelos 26 estados brasileiros no período de 2003 a 2014, compreendendo três ciclos eleitorais. Utilizou-se como metodologia a técnica de regressão com dados em painel.

Baseada nas análises descritiva e estatística, essa pesquisa concluiu que o fator mandato eleitoral exerce influência significativa sobre os gastos com investimentos. Os sinais dos parâmetros estimados permitem concluir que os gestores que exercem o primeiro mandato e estão em anos eleitorais alteram a composição dos gastos públicos em direção aos investimentos. 
Esse achado confirma o pressuposto de que os gestores aptos a concorrer à reeleição possuem maiores incentivos para manipular gastos públicos em períodos eleitorais. A variação aumentativa ocorreu justamente nos investimentos, que consistem em gastos finais facilmente perceptíveis pela sociedade. Os resultados obtidos por essa pesquisa estão alinhados com diversas pesquisas nacionais e internacionais (Drazen \& Eslava, 2010; Queiroz, 2015; Veiga \& Veiga, 2007; Vicente \& Nascimento, 2012), que apontam os investimentos como o principal gasto manipulável pelos gestores públicos em períodos eleitorais.

Essa pesquisa contribuiu com a literatura nacional sobre ciclos político-orçamentários na medida em que identificou o mandato eleitoral como um fator capaz de influenciar os gastos públicos estaduais nos períodos eleitorais. Os resultados dessa pesquisa, associados aos resultados obtidos por Klein e Sakurai (2015), permitem concluir que, tanto a nível municipal quanto estadual, existe uma manipulação da composição dos gastos públicos em direção aos investimentos nos anos eleitorais nos governos cujos gestores então em primeiro mandato.

A Emenda Constitucional 16/1997 (Emenda da Reeleição) representou um importante fator de mudança institucional, estabelecendo uma nova dinâmica nas disputas eleitorais (Nakaguma \& Bender, 2010). As evidências obtidas pela presente pesquisa, combinadas às anteriores (Klein \& Sakurai, 2015; Nakaguma \& Bender, 2010), levantam o questionamento acerca do impacto da reeleição sobre as finanças públicas, uma vez provou-se que o gestor apto a concorrer à reeleição comporta-se de forma oportunista. Deve-se refletir também sobre a eficácia da Lei 9.504/1997, que estabelece normas para as eleições, para limitar e coibir determinados comportamentos durante o período eleitoral por parte dos gestores.

A compreensão sobre como fatores políticos, tais como o mandato eleitoral, influenciam a dinâmica dos gastos públicos torna-se relevante considerando o cenário de restrições orçamentárias impostas às organizações públicas pela legislação brasileira, a exemplo da Constituição Federal de 1988, da Lei de Responsabilidade Fiscal, Lei Eleitoral, entre outras. Tais restrições limitam a discricionariedade do gestor para manipular os gastos públicos. Nesse sentido, essa pesquisa contribui com a literatura nacional ao identificar comportamentos oportunistas por parte dos gestores, mesmo considerando o cenário de pequena discricionariedade para alocar os recursos públicos.

Sugere-se, para pesquisas futuras, a verificação da influência do mandato eleitoral sobre gastos não considerados pela presente pesquisa e por Klein e Sakurai (2015). Os estudos podem abordar as diversas funções orçamentárias que compõem a classificação funcional da despesa pública. Essa abordagem pode ser realizada tanto a nível estadual quanto municipal.

\section{REFERÊNCIAS}

Alt, J. E., \& Lassen, D. D. (2006). Transparency, political polarization, and political budget cycles in OECD countries. American Journal of Political Science, 50(3), 530-550.

Arvate, P. R., Mendes, M., \& Rocha, A. (2010). Are voters fiscal conservatives? Evidence from Brazilian municipal elections. Estudos Econômicos, 40(1), 67-101.

Brender, A. (2003). The effect of fiscal performance on local government election results in Israel: 1989-1998. Jouunal of Public Economics, 87, 2187-2205.

Brender, A., \& Drazen, A. (2005). Political budget cycles in new versus established democracies. Journal of Monetary Economics, 52, 1271-1295.

Brender, A., \& Drazen, A. (2008). How do budget deficits and economic growth affect reelection prospects? Evidence from a large panel of countries. The American Economic Review, 98(5), 2203-2220.

Brender, A., \& Drazen, A. (2013). Elections, leaders, and the composition of government spending. Journal of Public Economics, 97, 18-31.

Brooks, C. (2014). Introductory Econometrics for Finance (3a ed.) Cambridge: Cambridge University Press. 
Constituição da República Federativa do Brasil de 1988. (1988). Recuperado em 29 de dezembro de 2017 de: http:// www.planalto.gov.br/ccivil_03/constituicao/constituicao.htm

Downs, A. (1957). An economic theory of political action in a democracy. Journal of Political Economy, 65(2), 135-150.

Drazen, A. (2001). The political business cycle after 25 years. NBER Macroeconomics Annual, 15, 75-138.

Drazen, A., \& Eslava, M. (2010). Marcela. Electoral manipulation via voter-friendly spending: theory and evidence. Jounal of Development Economics, 92, 39-52.

Gonzalez, P., Hindriks, J., \& Porteiro, N. (2013). Fiscal decentralization and political budget cycles. Journal of Public Economic Theory, 15(6), 884-911.

Haan, J. (2013). Democracy, elections and government budget deficits. German Economic Review, 15(1), 131-142.

Hibbs, D. A., Jr. (1977). Political parties and macroeconomic policy. American Political Science Review, 71(4), 1467-1487.

Katsimi, M., \& Sarantides, V. (2012). Do elections affect the composition of fiscal policy in developed, established democracies? Public Choice, 151, 325-362.

Klein, F. A. (2010). Reelection incentives and political budget cycle: evidence from Brazil. Revista de Administração Pública, 44(2), 283-337.

Klein, F. A., \& Sakurai, S. N. (2015). Term limits and political budget cycles at the local level: evidence from a young democracy. European Journal of Political Economy, 37, 21- 36.

Klomp, J., \& Haan, J. (2013). Political budget cycles and election outcomes. Public Choice, 157, 245-267.

Lei no 4.320, de 17 de março de 1964. (1964). Estatui Normas Gerais de Direito Financeiro para elaboração e controle dos orçamentos e balanços da União, dos Estados, dos Municípios e do Distrito Federal.

Lei no 9.504, de 30 de setembro de 1997. (1997). Estabelece normas para as eleições.

Macrae, D. (1977). A political model of the business cycle. Journal of Political Economy, 85(2), 239-263.

Nakaguma, M. Y. \& Bender, S. (2006). A emenda da Reeleição e a Lei de Responsabilidade Fiscal: Impactos sobre Ciclos Políticos e Performance Fiscal dos Estados (1986 - 2002). Revista de Economia Aplicada, 10(3), 377-397.

Nakaguma, M. Y. \& Bender, S. (2010). Ciclos Políticos e Resultados Eleitorais: Um Estudo sobre o Comportamento do Eleitor Brasileiro. Revista Brasileira de Economia, 64(1), 3-24.

Nordhaus, W. D. (1975). The political business cycle. Review of Economic Studies, 42(2), 169-190.

Peltzman, S. (1992). Voters as fiscal conservatives. The Quarterly Journal of Economics, 107(2), 327-361.

Portaria Interministerial $\mathrm{n}^{\circ} 163$, de 4 de maio de 2001. (2001). Dispõe sobre normas gerais de consolidação das Contas Públicas no âmbito da União, Estados, Distrito Federal e Municípios, e dá outras providências. Diário Oficial [da] República Federativa do Brasil. Brasília, DF: Ministério da Fazenda. Ministério do Planejamento, Orçamento e Gestão.

Queiroz, D. B. (2015). Composição dos Gastos Públicos e Resultados Eleitorais: Um estudo nos municípios brasileiros. (Tese de Doutorado). Universidade de Brasília, Universidade Federal da Paraíba e Universidade Federal do Rio Grande do Norte, Brasília, DF, Brasil.

Rogoff, K. (1990). Equilibrium political budget cycles. The American Economic Review, 80(1), 21-26.

Rogoff, K., \& Sibert, A. (1988). Elections and macroeconomic policy cycles. Review of Economic Studies, 55(1), 1-16.

Rose, S. (2006). Do fiscal rules dampen the political business cycle? Public Choice, 128, 407- 431.

Sakurai, S. N. (2005). Testando a hipótese de ciclos eleitorais racionais nas eleições dos municípios paulistas. Estudos Econômicos, 35(2), 297-315.

Sakurai, S. N. (2009). Ciclos políticos nas funções orçamentárias dos municípios brasileiros: uma análise para o período 1990 - 2005 via dados em painel. Estudos Econômicos, 39(1), 39-58.

Sakurai, S. N., \& Menezes, N. A., Filho. (2008). Fiscal policy and reelection in Brazilian municipalities. Public Choice, $137,301-314$. 
Sakurai, S. N., \& Menezes, N. A., Filho. (2011). Opportunistic and partisan election cycles in Brazil: new evidence at the municipal level. Public Choice, 148, 233-247.

Saporiti, A., \& Streb, J. M. (2008). Separation of powers and political budget cycles. Public Choice, 137, 329-345.

Schneider, C. J. (2010) Fighting with one hand tied behind the back: political budget cycles in the West German states. Public Choice, 142, 125-150.

Shi, M., \& Svensson, J. (2006). Political budget cycles: do they differ across countries and why? Journal of Public Economics, 90, 1367-1389.

Streb, J. M., \& Torrens, G. (2013). Making rules credible: divided government and political budget cycles. Public Choice, 156, 703-722.

Veiga, L. G., \& Veiga, F. J. (2007a). Does opportunism pay off? Economics Letters, 96, 177-182.

Veiga, L. G., \& Veiga, F. J. (2007b). Political business cycles at the municipal level. Public Choice, 131, 45-64.

Vergne, C. (2009). Democracy, elections and allocation of public expenditures in developing countries. European Journal of Political Economy, 25, 63-77.

Vicente, E. F. R., \& Nascimento, L. S. (2012). A efetividade dos ciclos políticos nos municípios brasileiros: um enfoque contábil. Revista de Contabilidade e Organizações, 6, 106- 126.

\section{BY-NC-ND}

